\title{
Renew or cancel? Applying a model for objective journal evaluation.
}

Abstract: Journal renewal period is September-October and arrives at a time when subject librarians are busy teaching and meeting with new students and faculty, leaving little time for anything else, especially making difficult decisions such as cancelling journals with an ever-rising price tag. We developed a cascading model for evaluating journal subscriptions. It is based on several variables, such as accessibility, value, price and usage. Paraprofessionals can populate the model with data, reducing the librarians' work considerably. The model was tested for print and e-journals, for small journals packages and large renewal lists.

Introduction and Background

The University of Ottawa, offering more than 450 programs in 10 faculties, is the largest bilingual (English-French) university in the world and among Canada's top 10 research universities. The library has a dozen locations: the Morisset library covers most disciplines and houses Archives and Special Collections, the Media Library and the Geographical, Statistical and Government Information Center; the Law Library, the Health Sciences Library, the Education Information Center and several libraries with very small or no physical collections such as Music, Management, Social Sciences, Heart Institute libraries. The library has also an off-campus storage facility, known as the Library Annex.

The Library has a rich collection of journals and subscribes to over 25,000 titles. Most of them are in bundled subscriptions, ranging from the common "big deals" offered by major academic publishers to consortia, in "small deals" as I like to call the packages offered by specialized publishers, which have from a dozen to 100 journals, through subscription agents, and direct from small publishers. An additional 75,000 journals are available through the different full-text databases to which we subscribe. More than ten years ago we adopted the online preferred format for journals in our collection development policy, so most of our journals are online. The Annex houses the bulk of the print copies, mainly back issues, and current print journals can be found in each library.

The collection manager team is headed by the Associate University Librarian for collections and three collection managers, one responsible for law, the second for health sciences and the third, for all the other subjects. Their decisions, based on input from the subject librarians, are in regards to multidisciplinary and consortia products. The subject specialists, responsible for one or more disciplines, are responsible for ensuring the collection development for each of their discipline, liaising with faculty, offering instruction and reference to students and faculty. The Acquisitions department is responsible for handling renewals. At the beginning of the fiscal year collection managers will decide upon the acceptable increase rate for periodicals, taking into account the current state of the budget, inflation, and the EBSCO serials price projection report. In previous years this rate was $6 \%$, meaning that if the price increase of a subscription was equal to or less than $6 \%$ the renewal is done automatically. If the increase is higher than the percentage that the collection managers have agreed upon, then acquisition clerks contact the collection managers/subject specialist and ask if that particular title should be renewed or cancelled. Most of our subscriptions, but not all of them, run on a calendar year, and so 
Acquisitions are busy with renewals in September-October. The renewal period coincides with the beginning of the new academic year, when subject librarians are very busy with instruction, reference and liaising with faculty and students. For this reason, they have little time or patience to deal with the ever-trickling "renew or cancel" questions acquisition clerks are sending to them. It is not surprising that the $6 \%$ increase is quite often surpassed for individual subscriptions and that some 500 subscriptions were questioned every fall. We proposed additional criteria for automatic subscription renewals - if the price of the journal is less than $\$ 150$ or if the increase is $\$ 50$ or less, independent of the increase rate. While the number of subscriptions questioned diminished under these new criteria, is still was a long and stressful process for all parties involved, with many e-mails and reminders being sent by Acquisitions. It was clear that another approach was needed and while price increase sometimes triggered a cancellation decision, it was often far from the most important factor. Following the 2014 fall journal renewal season, we decided that, as five years had passed since we had last looked at our individual journal subscriptions, to review them during the next summer.

Model Development

The immediate question arising is how to decide if a journal should be kept in our collection or cancelled? While most librarians enjoy developing collections, weeding is the part of the job that they avoid as much as possible. There isn't any positive recognition from our users for this task. How many times have we heard "thank you for cancelling database ABC" or for weeding the 1995 edition of the XYZ yearbook? Even sending books to the off-storage facility, from which they can be retrieved in 24 hours, is met with resistance from faculty. Moreover, we noticed in the last few years a significant turnover for subject specialists, due to retirements, academic and other types of leave. While the more experienced librarians have developed their own criteria for assessing a journal, the new librarians needed a document to which they could refer in order to ensure consistency and objectivity in decision making. There was a clear need for an objective process on which to base the review of our individual subscription. After their own assessment, subject specialists could go back to the faculty and present the list of the potential candidates for cancellations, as well as the rationale for it.

The model was developed during the summer of 2014 and first tested on the group of journals acquired through, at that time, our major subscription agent. The following is a snapshot of the 1,525 journals with an active subscription:

- $\quad$ Language of publication - 1,013 English, 377 French and 135 other languages

- $\quad 1,085$ print, 245 online, 194 print + online, 1 CD-ROM

- $\quad 347$ were available through an aggregator, 95 had an embargo varying from 1 to 12 months. Journals with aggregator access with an embargo of more than 12 months were considered as not having aggregator access. 
- $\quad 866$ were not available online nor included in any database aggregator. Some titles might offer online access, but only to individual IPs, thus making the online version unusable for the library. Some journals might be available through aggregators, with an embargo of more than 12 months.

- 292 titles have no payment information for FY2014, and 152 no payment information for both FY2013 and FY2014. Reasons for no payment information included irregular or delayed publication, or journal paid with another subscription.

- $\quad$ Median price was \$124 in FY2013 \$131 in FY2014

While the amount spent on these subscriptions represented less than $3 \%$ of our acquisition budget, it was still an important amount in absolute numbers - $\$ 400,000$ spent for these subscriptions in FY2014.

Literature review

Few recent articles discuss print journal cancellations. Vandale and Minchew (2014) recorded for a period of 4 months print usage of journals and then asked faculty to identify from lists the most and the least important journals. Matlak (2010) mentions that the most often cited guidelines for objective weeding are "relevance to curriculum, lack of use evidenced by the "dust test" and circulation records, economic and archival value of items, archival quality digital copy available on the Internet/hard copy at other Libraries, "Obsolescence" in light of current scholarship determined by age, citation analysis, and lack of indexing." Many more articles are dedicated to the so-called "big deals", the ejournal bundles that major commercial publishers are selling to academic libraries. Wilson and Li (2012) reported on the experience of the California Digital Library in the development of a model of value-based pricing that takes in consideration six metrics: usage, citations, impact factor; SNIP, cost per use and cost per SNIP. Lorenz (2014) presented the Data Envelopment Analysis model, which could have combined library data relating the author, reader and publisher in one ranking. This model seemed perfect from a theoretical point of view, but in reality it wasn't at all practical.

Our goal was to develop a model complex enough to integrate all factors, highly flexible and easy to apply. We constructed our model on five main factors: pertinence, availability, value, price and usage. Instead of trying to develop a ranking system, which could have been very difficult and unpractical, we developed a cascading model. Depending on intermediary results, a decision could be reached earlier in the process without passing through all the steps.

\section{Pertinence}

Foremost, journals should be pertinent to programs taught at the university and align with the research interests of our users. In the same way we subscribe to new journals when a new program is developed or a new professor joins a department, we should also cancel a journal when a program gets dropped, a professor retires or leaves or when research interests change. Journals that don't support a program or a research interest should be cancelled. After assessing pertinence to current programs and research 
interests, the following criteria should be considered when making the retention or cancellation decisions.

Availability

Our collection development policy states that the online format is preferred over print for journals and that print subscriptions are cancelled when the online format becomes available. However, there are rare instances and compelling reasons to keep the print. Additional access through aggregators should be considered. A period of up to 12-months embargo is an acceptable period for many disciplines, especially when the journal is available only in paper. New online issues might actually become available quicker than the paper issue in the stacks. If a journal is available through an aggregator without embargo or with an acceptable embargo delay it becomes a very good candidate for cancellation. The confidence that a journal will be always included in a full-text database is a topic that could be debated, however it shouldn't prevent us from cancelling a journal. In the event that the journal is dropped from a full-text database the Library could always re-subscribe.

Value

Assessing value for a journal isn't an easy or straightforward process, as there are different criteria we could use. We have identified three we consider primary criteria: inclusion in bibliometric analysis databases, inclusion in $\mathrm{A} / \mathrm{I}$ databases to which we subscribe and journals with peer review process. Additionally, we selected two secondary criteria which have a certain importance for our environment: publication language and publisher.

The two bibliometric analysis databases we refer to are the Journal Citation Reports (JCR) and Scopus. Both have strict selection processes and we can rely upon their process to consider that a journal included in one or both databases is valuable. While we recognize that there has been much discussion around the impact factor and its limitations, it is still a very well recognized and respected criterion by faculty. Each year Thomson Reuters publishes the list of periodicals included in the current release of JCR. Even if a library subscribes to JCR, generating a journal list is virtually impossible. Using the JCR list freely available on the web and formatting it from the pdf to the Excel format is the best solution for subscribers and non-subscribers alike. However this list has very limited useful information: journal title, country of publication and domain of knowledge (science/social science). Scopus publishes two to three times a year updates to its journal list, which includes a great deal of additional information, such as coverage, ISSN, publisher, open access status, as well as the journal metrics Source Normalized Impact (SNIP), Impact per Publication (IPP), SClmago Journal Rank (SJR) for the last three years. Scopus has a greater coverage than JCR, however it doesn't index all the JCR titles, so using both databases is useful. 
Journals should be indexed in abstracting and indexing $(\mathrm{A} / \mathrm{I})$ databases to which we subscribe, as students couldn't discover them otherwise. It might be conceivable that in smaller libraries with specialized clientele print journals not indexed in any database would still be used by students or faculty; however, in the larger libraries, such as Morisset Library, this is hardly plausible.

Peer-reviewed journals have obviously a higher value than newsletters or trade journals, however there are cases when non peer-reviewed journals are important for teaching or research.

Language is an important criterion for our library, as we are a bilingual institution and strive to build a robust French language research collection. Journals published in languages other than English could be more valuable, as they would make differ our collection from collections of other universities. Journals published by university departments or reputable bodies, such as associations, etc. could represent an additional value.

When assessing the value of a journal we can take in consideration all factors or limit ourselves to only a few. New or recent journals will not have any bibliometric information, so in the other factors will play a larger part in determining value. Each library can add their factors that are important in their community, such as faculty on editorial board, publication with a regional focus, etc.

Price

As mentioned earlier, price should be only one of the factors used to decide whether a journal is renewed or cancelled. Historical prices can give a general idea about the price fluctuations of a journal. Journals costing less than $\$ 100$ would be considered inexpensive and those priced between $\$ 100-\$ 250$ would be considered affordable. Usually, these journals are published by not-for-profit associations and university departments. Journals are inexpensive or affordable more often for some disciplines (Arts) than for others (Medicine). We shouldn't take into consideration only the absolute price of the journal. We took our inspiration from the online tool Bergstrom developed (journalprices.com) and decided to adopt a more accurate measure than price, namely cost/article, taking into consideration the number of articles published in one year. For a peer-reviewed journal the definition of article would exclude editorials, books reviews, letters, etc. This definition can vary by discipline. For journals that are not referred the definition of articles includes all articles.

In order to determine the threshold price for calculating the cost/article we looked at the cost of acquiring an individual article directly through pay-per-view instead of the traditional Interlibrary Loan (ILL) method from another library. This cost usually varies between $\$ 30-\$ 60$. Most journals publish at least 6-10 articles/year. For practical purposes, we thus propose to use the cost/article metric only for journals with annual prices over $\$ 250$. 
The cost/article is calculated by dividing the price paid for the journal with the total number of articles published in that year. SCImago Journal and Country Rank (http://www.scimagojr.com) uses the Scopus data to calculate the SJR journal metric. The journal list that can be freely downloaded from its website includes also the number of articles in the last three years and in the last year. As the number of articles published in a year can vary significantly from year to year we have used the average of the last three years. The cost/article is considered inexpensive if the cost/article is less than $\$ 10$; affordable if it is between $\$ 10-\$ 30$ and expensive if the cost/article is over $\$ 30$.

Usage

The journals we used in developing the model were $71 \%$ in paper format only, so usage was not available, as we don't gather usage statistics for print journals. Our link-resolver is SFX and we could use SFX query 12, journals requested with no full text available, to find if the full text of a particular journal has been requested by users. These requests would originate from databases, so journals not indexed in subscribed databases wouldn't show up in the SFX query 12.

Journals covered by aggregators have the advantage of offering usage reports in Counter-compliant format. The Library gathers statistics by using journal report JR1. This reports usage data for all articles, regardless of the year of publication. Report JR5 differentiate by publication year, but we don't collect this data as of now. Low usage might indicate that there is little interest for those periodicals, or that the aggregators offer only a limited number of years and not the full run. Higher usage might indicate a high interest for those periodicals, though usage might be fueled by online availability.

Most online journals don't offer COUNTER-compliant usage statistics or don't offer any statistics at all. SFX query 19 lists online journals that have at least one SFX request in a given month. Usage is recorded as the number of click-throughs. For online journals that are accessed directly on the campus without passing through the SFX menu, usage statistics are counted only on the publisher's platform.

Not only are usage statistics hard or impossible to obtain, we should also remember that usage doesn't define value for faculty.

\section{Discussion and results}

The final model is thus comprised of five main parts which form a decision tree (see Appendix 1), easily adaptable to locally defined or specific circumstances. The parts can be hidden (ignored), moved higher or lower in the decision tree, according to the importance each library gives to a certain criterion.

Once the model was developed, data from all different sources were pulled together in one Excel spreadsheet. The Excel sheet included the following information: journal title, ISSN, language, LC call 
number, LC subject heading, fund code, format, order number, bib number, amount paid in the previous year, currency, acquisition notes - all provided from the integrated library system (ILS). Data also came from the JR1 usage reports for EBSCO, ProQuest, Gale and JSTOR. The Scopus journal list provided information about the Scopus indexing status (active, non-active or never indexed), SNIP and SJR. From SCImago website we obtained a list with the number of citable articles in the past three years. Aggregator access was supplied by the acquisition department. We indicated in one of the columns if the journal was included in JCR. We first intended to use the ISSN as the unique identifier, but this wasn't possible, as one source wouldn't list any ISSN, another would have only print ISSN, a third would have both print as online ISSN and the information from the ILS pulled all the ISSNs into one cell, ignoring all the initial zeros. We didn't try cleaning up the data by using a data cleaner such as OpenRefine, but preferred to use the title as the unique identifier. By sorting and combing data we were able to identify what journals we would renew and what journals needed more information. We searched Ulrich's Periodicals Directory to determine if the journal was peer-reviewed and if it was indexed in our databases. This step was time-consuming, however student workers performed it diligently and librarians made quickly decisions for the journals in their discipline. By the end of this exercise we identified a quarter of the journals that could be cancelled.

This model has since been used for evaluating individual new subscriptions and two "small deals" and we intend to use it in future journal assessment. The modular form is very flexible and can be easily adapted to print or online journals. The cascading model eliminates the ranking of journals that aren't compared to each other anymore but are each evaluated on its own. It is especially useful when applied to a heterogeneous collection of journals.

\section{References}

Lorenz, M. (2014) A method for journal collection management and the limitations of reality.

Qualitative and Quantitative Methods in Libraries, 1, 321 -330. http://www.qqml.net/papers/March_2014_Issue/3117QQML_Journal_2014_Lorenz_321-330.pdf

Matlak, J. (2010) Weeding older social sciences journals. Behavioral \& Social

Sciences Librarian, 29(3), 169-183. http://dx.doi.org/10.1080/01639269.2010.498762

Vandale, S. \& Minchew, T. (2014) It's not just about budget cuts: a study of print periodical usage and a subsequent cancellation project at a small academic library. Serials Review, 40(3), 203-206.

Doi:10.1080/00987913.2014.949560

Wilson, J. \& Li, C. (2012) Calculating scholarly journal value through objective metrics. California Digital Library, http://www.cdlib.org/cdlinfo/2012/02/13/calculating-scholarly-journal-value-throughobjective-metrics/.

[Insert Appendix 1 here] 
Appendix 1. Decision tree for evaluating journal subscriptions

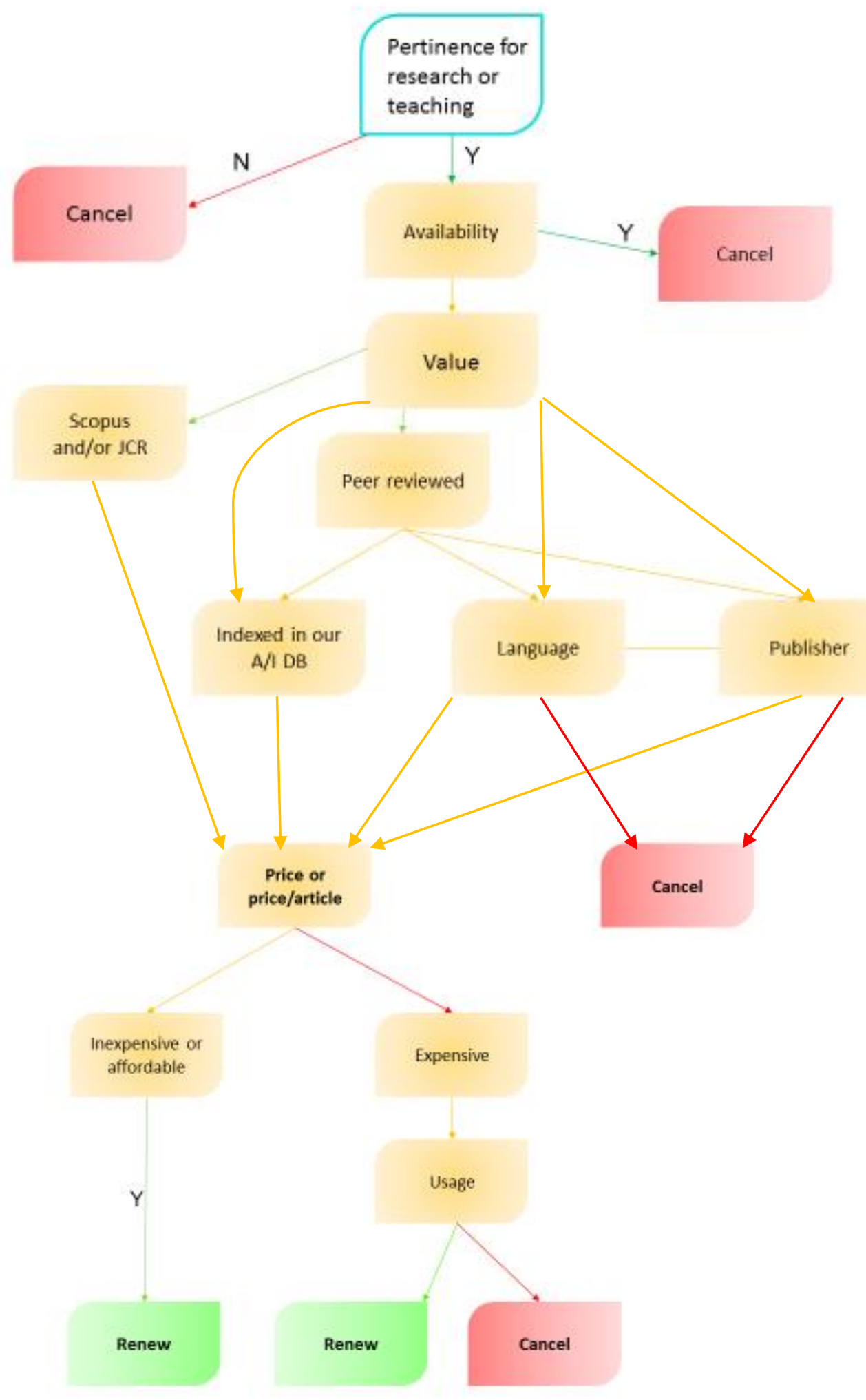


Green arrow stands for Yes, red arrow stands for No, and orange arrow stands for additional decision making.

A journal would be evaluated by descending the decision tree. One of the many possible routes could be the following:

If the journal is pertinent to current programs and research interest, availability is considered. If it isn't, it will be cancelled.

If a journal is available through aggregators, it will be cancelled.

If a journal isn't available through an aggregator, value is considered.

If the journal is available in JCR and/or Scopus, price is considered.

If the journal isn't available in JCR and/or Scopus, is the journal peer-reviewed?

If the journal is peer-reviewed or not, additional information regarding indexation in $\mathrm{A} / \mathrm{I}$ databases, language and publisher is taken in consideration to establish value.

If the journal isn't valuable it will be cancelled.

If the journal is valuable, price is considered.

If the price or price/article is inexpensive or affordable, the journal is renewed.

If the price is expensive, usage data is considered.

Usage data, as well as all the other previous factors, will determine if the journal is cancelled or renewed. 